Pacific Journal of Mathematic 


\section{GENERALIZATION OF A THEOREM OF McFADDEN}

\section{INDULATA SUKLA}

McFadden's relation $|N, 1 /(n+1)| \subset|C, k|(k>0)$ is strengthened to $\left|N, p_{n}\right| \subset|R, \lambda(w), k|(k>0)$ for suitable $\left\{p_{n}\right\}$ and $\lambda(w)$.

1. Let $\left\{p_{n}\right\}$ be a sequence of complex numbers such that for $n>0$,

$$
P_{n}=p_{0}+p_{1}+\cdots+p_{n} \neq 0 .
$$

Let $\sum_{n=0}^{\infty} a_{n}$ be an infinite series with $\left\{s_{n}\right\}$ as its partial sums. We define the $\left(N, p_{n}\right)$-transform $\left\{t_{n}\left(s_{n}\right)\right\}$ of $\left\{s_{n}\right\}$ generated by the sequence $\left\{p_{n}\right\}$ by the formula

$$
t_{n}\left(s_{n}\right)=\frac{1}{P_{n}} \sum_{v=0}^{n} p_{n-v} s_{v} .
$$

Similarly, $\left\{t_{n}\left(n a_{n}\right)\right\}$ denotes the $\left(N, p_{n}\right)$-transform of the sequence $\left\{n a_{n}\right\}$ generated by the sequence $\left\{p_{n}\right\}$. The series $\sum_{n=0}^{\infty} a_{n}$ is said to be summable $\left|N, p_{n}\right|$ if $\left\{t_{n}\left(s_{n}\right)\right\} \in B V$, i.e., $\sum_{n=1}^{\infty}\left|t_{n}-t_{n-1}\right|$ is convergent. (See [7], [5].) In the special case when $p_{n}=\left(\begin{array}{c}n+k-1 \\ k-1\end{array}\right)$, $(k>-1)$, summability $\left|N, p_{n}\right|$ is summability $|C, k|$.

Let $\lambda=\lambda(w)$ be a differentiable, monotonically increasing function of $w$ in $(A, \infty)$, where $A$ is a finite positive number; and let $\mu(w)$ be its differential and let $\lambda(w)$ tend to infinity with $w$. For $k \geqq 0$, we write

$$
R_{\lambda}^{k}(w)=\sum_{n \leq w}\{\lambda(w)-\lambda(n)\}^{k} a_{n} .
$$

The series $\sum_{n=0}^{\infty} a_{n}$ is said to be summable $|R, \lambda, k|$ if

$$
\int_{A}^{\infty}\left|d\left[R_{\lambda}^{k}(w) / \lambda^{k}(w)\right]\right|<\infty,
$$

see [8], [9]. For $k>0, N<w<N+1(N=1,2, \cdots)$

$$
\frac{d}{d w}\left[R_{\lambda}^{k}(w) / \lambda^{k}(w)\right]=\frac{k \mu(w)}{\lambda^{k+1}(w)} \sum_{n \leqq w}\{\lambda(w)-\lambda(n)\}^{k-1} \lambda(n) a_{n} .
$$

Hence, summability $|R, \lambda, k|$ is equivalent to the convergence of the integral

$$
\int_{A}^{\infty} \frac{\mu(w)}{\lambda^{k+1}(w)}\left|\sum_{n \leq w}\{\lambda(w)-\lambda(n)\}^{k-1} \lambda(n) a_{n}\right| d w .
$$

If every series summable by the method $P$ is summable by the 
method $Q$, we write $P \subseteq Q$. If $P \subseteq Q$ and $Q \subseteq P$, we write $P \sim Q$. We now define a sequence of constants $\left\{c_{n}\right\}$ by the identity

$$
\left[\sum_{n=0}^{\infty} p_{n} x^{n}\right]^{-1}=\sum_{n=0}^{\infty} c_{n} x^{n}, \quad c_{-1}=0 .
$$

If, for $n=0,1,2, \cdots$

$$
p_{n}>0, \frac{p_{n+1}}{p_{n}} \leqq \frac{p_{n+2}}{p_{n+1}} \leqq 1,
$$

we shall write $\left\{p_{n}\right\} \in \mathscr{M}$. We write

$$
\begin{aligned}
& d_{n}=c_{0}+c_{1}+\cdots+c_{n} ; \\
& e_{n}=d_{0}+d_{1}+\cdots+d_{n} .
\end{aligned}
$$

We write $P(v), d(v), e(v)$ in place of $P_{v}, d_{v}, e_{v}$ respectively when $v$ is replaced by a more complicated expression. We let $\Delta f_{n}=f_{n}$ $f_{n+1}$, for any sequence $\left\{f_{n}\right\}$.

The following inclusion theorems are known:

$$
|C, 0| \subset\left|N, \frac{1}{n+1}\right| \subset|C, k| \sim|R, n, k|,(k>0) .
$$

The first one is due to Mears [6], the second one is due to McFadden [4] and the equivalence is due to Hyslop [3].

Our object is to prove that under certain conditions on $\left\{p_{n}\right\}$ and $\lambda(w)$,

$$
\left|N, p_{n}\right| \subset|R, \lambda(\omega), k|(k>0) .
$$

2. We establish the following.

THEOREM. Let

$$
\begin{gathered}
\left\{p_{n}\right\} \in \mathscr{C}, \\
P\left(v^{2}\right)=O\left(P_{v}\right),
\end{gathered}
$$

$\lambda(w)$ be an indefinite integral of some function $\mu(w)$,

$$
(n+1)\left\{\frac{\lambda(n+1)-\lambda(n)}{\lambda(n+1)}\right\}=O(1) .
$$

Then $\left|N, p_{n}\right|$ implies $|R, \lambda(w), k|$ for all $k>0$.

For the proof we require the following lammas.

Lemma 1 [1]. Let $\left\{p_{n}\right\} \in \mathscr{M} . A$ necessary and sufficient condi- 
tion for $\Sigma a_{n} \in\left|N, p_{n}\right|$ is

$$
\sum_{n=1}^{\infty} \frac{\left|t_{n}\left(n a_{n}\right)\right|}{n}<\infty
$$

Lemma $2[1]$. Let $\left\{p_{n}\right\} \in \mathscr{L}$. Then

(i) $c_{0}>0, c_{n} \leqq 0(n=1,2,3, \cdots)$

(ii) $\sum_{n=v+1}^{\infty}\left|c_{n}\right| \leqq d_{v}$

(iii) $d_{n} \geqq 0$ and monotonic nonincreasing

(iv) $P_{n} d_{n} \leqq 1$

(v) $P_{n} e_{n} \leqq(2 n+1)$.

For (i), (ii) see Hardy [2] Theorem 22, p. 68.

Lemma 3. Let $\left\{p_{n}\right\} \in \mathscr{l}$. Then for any fixed $k$ with $0<k<1$, (2.2) is equivalent to

$$
P_{v}=O(P(u)), \text { where } u=\left[v^{k}\right] .
$$

Proof. If (2.2) holds, by successive application of (2.2) we see that for any fixed integer $r$,

$$
P\left(v^{2^{r}}\right)=O\left(P_{v}\right) \text {. }
$$

Choose $r$ so that $2^{r}>1 / k$. Then if $u=\left[v^{k}\right], v \leqq(u)^{1 / k}<(u)^{2^{r}}$. So, since $P_{v}$ is increasing, (2.5) follows from (2.6).

Conversely, suppose that (2.5) holds. Given any positive integer $v$, define $v_{r}$ inductively (on $r$ ) by taking $v_{0}=v$ and defining $v_{r}(r>1$ ) as the least integer greater than or equal to $v_{r-1}^{1 / k}$. Since $\left\{p_{n}\right\} \in \mu$ implies that

$$
\frac{p_{r}}{p_{r-1}} \longrightarrow 1
$$

as $r \rightarrow \infty$, we see that (2.5) is equivalent to

$$
P\left(v_{1}\right)=O\left(P_{v}\right) \text {. }
$$

By successive application of (2.8) we deduce that, for any fixed $r$,

$$
P\left(v_{r}\right)=O\left(P_{v}\right) \text {. }
$$

Choose $r$ so that $(1 / k)^{r}>2$. Then $v_{r}>v^{2}$ so that (again since $P_{v}$ is increasing) (2.9) implies (2.2).

For the proof of the theorem we require (2.5). The condition (2.2) is preferable to (2.5) because the former is simpler and independent of $k$. 
LEMMA 4. If (2.4) is satisfied then

$$
\frac{\lambda(n+1)}{\lambda(n)}=O(1) \text {, as } n \longrightarrow \infty \text {. }
$$

This is obvious.

3. Proof of the theorem. It is enough to consider the case $0<k<1$. This implies the result for $k \geqq 1$. We can assume without loss of generality that $a_{0}=0$. Then by Lemma 1 and (1.2) it is enough to show that $\left(2.4^{\prime}\right)$ implies

$$
\int_{1}^{\infty}\left|\frac{d}{d w}\left(R_{\lambda}^{k}(w) / \lambda^{k}(w)\right)\right| d w<\infty
$$

Now,

$$
n a_{n}=\sum_{v=1}^{n} c_{n-v} P_{v} t_{v}\left(v a_{v}\right)
$$

Then

$$
\begin{gathered}
\frac{d}{d w} \frac{R_{\lambda}^{k}(w)}{\lambda^{k}(w)}=\frac{k \mu(w)}{\lambda^{k+1}(w)}\left[\sum_{n=1}^{[w]}\{\lambda(w)-\lambda(n)\}^{k-1} \frac{\lambda(n)}{n} \sum_{v=1}^{n} c_{n-v} P_{v} t_{v}\left(v a_{v}\right)\right] \\
=\frac{k \mu(w)}{\lambda^{k+1}(w)}\left[\sum_{v=1}^{[w]} P_{v} t_{v}\left(v a_{v}\right) \sum_{n=v}^{[w]}\{\lambda(w)-\lambda(n)\}^{k-1} \frac{\lambda(n)}{n} c_{n-v}\right] .
\end{gathered}
$$

Then

$$
\begin{aligned}
& \int_{1}^{\infty}\left|\frac{d}{d w}\left(R_{\lambda}^{k}(w) / \lambda^{k}(w)\right)\right| d w \\
& \quad=O(1)\left[\int_{1}^{\infty} \frac{\mu(w)}{\lambda^{k+1}(w)} \sum_{v=1}^{[w]} v P_{v} \frac{\left|t_{v}\left(v a_{v}\right)\right|}{v}\left|\sum_{n=v}^{[w]}\{\lambda(w)-\lambda(n)\}^{k-1} \frac{\lambda(n)}{n} c_{n-v}\right| d w\right] \\
& \quad=O(1)\left[\sum_{v=1}^{\infty} v P_{v} \frac{\left|t_{v}\left(v a_{v}\right)\right|}{v} \int_{v}^{\infty} \frac{\mu(w)}{\lambda^{k+1}(w)}\left|\sum_{n=v}^{[w]}\{\lambda(w)-\lambda(n)\}^{k-1} \frac{\lambda(n)}{n} c_{n-v}\right| d w\right] .
\end{aligned}
$$

Thus it is enough to prove that uniformly in $v \geqq 1$,

$$
\begin{aligned}
J(v) & =\int_{v}^{\infty} \frac{\mu(w)}{\lambda^{k+1}(w)}\left|\sum_{n=v}^{[w]}\{\lambda(w)-\lambda(n)\}^{k-1} \frac{\lambda(n)}{n} c_{n-v}\right| d w \\
& =O\left(\frac{1}{v P_{v}}\right) .
\end{aligned}
$$

Write $m=\min ([w], v+u)$. Let $a=v+u-1, b=v+u+1$.

Applying partial summation to the sum over the range $v \leqq n \leqq$ $m$, we see that the expression inside the modulus in (3.1) is equal to 


$$
\begin{aligned}
& \sum_{n=v}^{m-1} \Delta_{n}\left[(\lambda(w)-\lambda(n))^{k-1} \frac{\lambda(n)}{n}\right] d_{n-v}+(\lambda(w)-\lambda(m))^{k-1} \frac{\lambda(m)}{m} d_{m-v} \\
& \quad+\sum_{n=m+1}^{[w]}(\lambda(w)-\lambda(n))^{k-1} \frac{\lambda(n)}{n} c_{n-v} \\
& =\sum_{n=v}^{m-1}(\lambda(w)-\lambda(n))^{k-1} \Delta\left(\frac{\lambda(n)}{n}\right) d_{n-v} \\
& \quad+\sum_{n=v}^{m-1} \Delta_{n}(\lambda(w)-\lambda(n))^{k-1} \frac{\lambda(n+1)}{n+1} d_{n-v} \\
& \quad+(\lambda(w)-\lambda(m))^{k-1} \frac{\lambda(m)}{m} d_{m-v}+\sum_{n=m+1}^{[w]}(\lambda(w)-\lambda(n))^{k-1} \frac{\lambda(n)}{n} c_{n-v} .
\end{aligned}
$$

Here the last term is to be omitted when $m=[w]$, i.e., when $w<b$. Hence

$$
J(v) \leqq J_{1}(v)+J_{2}(v)+J_{3}(v)+J_{4}(v),
$$

where $J_{1}(v), J_{2}(v), J_{3}(v), J_{4}(v)$ denote the expressions obtained by replacing the expression inside the modulus in (3.1) by each of the four terms on the right of (3.2). First,

$$
\begin{aligned}
J_{1}(v) & \leqq \sum_{n=v}^{a} d_{n-v}\left|\Delta\left(\frac{\lambda(n)}{n}\right)\right| \int_{n+1}^{\infty} \frac{(\lambda(w)-\lambda(n))^{k-1} \mu(w)}{\lambda^{k+1}(w)} d w \\
& =O(1) \sum_{n=v}^{a} d_{n-v} \frac{|\Delta \lambda(n)|}{(n+1) \lambda(n)}+O(1) \sum_{n=v}^{a} d_{n-v} \frac{\lambda(n)}{n(n+1) \lambda(n)} .
\end{aligned}
$$

Using (2.4) and Lemma 4,

$$
\begin{aligned}
J_{1}(v) & =O(1) \sum_{n=v}^{a} \frac{d_{n-v}}{n^{2}} \\
& =O(1) \frac{e(u-1)}{v^{2}}=O\left(\frac{1}{v P_{v}}\right),
\end{aligned}
$$

by Lemma $2(\mathrm{v})$ and Lemma 3. Next,

$$
\begin{aligned}
J_{2}(v) & \leqq \sum_{n=v}^{a} d_{n-v} \frac{\lambda(n+1)}{n+1} \\
& \times \int_{n+1}^{\infty} \frac{\left[(\lambda(w)-\lambda(n+1))^{k-1}-(\lambda(w)-\lambda(n))^{k-1}\right] \mu(w)}{\lambda^{k+1}(w)} d w .
\end{aligned}
$$

The inner integral can be evaluated and is equal to

$$
\begin{aligned}
& \frac{1}{k}\left[\frac{1}{\lambda(n+1)}-\frac{1}{\lambda(n)}\left\{1-\left(\frac{\lambda(n+1)-\lambda(n)}{\lambda(n+1)}\right)^{k}\right\}\right] \\
& =\frac{1}{k \lambda(n)}\left[\left(\frac{\lambda(n+1)-\lambda(n)}{\lambda(n+1)}\right)^{k}-\left(\frac{\lambda(n+1)-\lambda(n)}{\lambda(n+1)}\right)\right] \\
& =O\left(\frac{1}{n^{k} \lambda(n)}\right),
\end{aligned}
$$


by (2.4). Hence, by Lemma 4,

$$
\begin{aligned}
J_{2}(v) & =O(1) \sum_{n=v}^{a} \frac{d_{n-v}}{n^{k+1}}=O(1) \frac{e(u-1)}{v^{k+1}} \\
& =O\left(\frac{1}{v P_{v}}\right),
\end{aligned}
$$

by Lemma $2(\mathrm{v})$ and Lemma 3.

Suppose $N \leqq w<N+1$. Then,

$$
\begin{aligned}
J_{3}(v) \leqq & \int_{v}^{v+u}(\lambda(w)-\lambda(N))^{k-1} \frac{\lambda(N)}{N} d_{N-v} \frac{\mu(w)}{\lambda^{k+1}(w)} d w \\
& +\frac{\lambda(v+u)}{v+u} d(u) \int_{v+u}^{\infty}(\lambda(w)-\lambda(v+u))^{k-1} \frac{\mu(w)}{\lambda^{k+1}(w)} d w \\
& =J_{31}(v)+J_{32}(v) .
\end{aligned}
$$

Since

$$
\int_{v+u}^{\infty}(\lambda(w)-\lambda(v+u))^{k-1} \frac{\mu(w)}{\lambda^{k+1}(w)} d w=\frac{1}{k \lambda(v+u)}
$$

clearly

$$
J_{32}(v)=O\left(\frac{d(u)}{v+u}\right)=O\left(\frac{1}{v P_{v}}\right)
$$

by Lemma 2(iv) and Lemma 3.

Now,

$$
\begin{aligned}
J_{31}(v) & \leqq \sum_{\sigma=0}^{u-1} \int_{v+\sigma}^{v+\sigma+1}(\lambda(w)-\lambda(N))^{k-1} \frac{\lambda(N)}{N} d_{N-v} \frac{\mu(w)}{\lambda^{k+1}(w)} d w \\
& \leqq \sum_{\sigma=0}^{u-1} \frac{d_{\sigma}}{(v+\sigma) \lambda^{k}(v+\sigma)} \int_{v+\sigma}^{v+\sigma+1}(\lambda(w)-\lambda(N))^{k-1} \mu(w) d w \\
& \leqq \sum_{\sigma=0}^{u-1} \frac{d_{\sigma}}{(v+\sigma) \lambda^{k}(v+\sigma)} \int_{v+\sigma}^{v+\sigma+1}(\lambda(w)-\lambda(N))^{k-1} \mu(w) d w \\
& =O(1) \sum_{\sigma=0}^{u-1} \frac{d_{\sigma}}{(v+\sigma) \lambda^{k}(v+\sigma)} \frac{\lambda^{k}(v+\sigma+1)}{(v+\sigma+1)^{k}} \\
& =O\left(\frac{1}{v P_{v}}\right),
\end{aligned}
$$

by Lemma 4, Lemma 2(v), and Lemma 3. Hence

$$
J_{3}(v)=O\left(1 / v P_{v}\right) .
$$

Lastly, 


$$
\begin{aligned}
J_{4}(v) & \leqq \int_{b}^{\infty} \frac{\mu(w)}{\lambda^{k+1}(w)}\left[\sum_{n=m+1}^{[w]}(\lambda(w)-\lambda(n))^{k-1} \frac{\lambda(n)}{n}\left|c_{n-v}\right|\right] d w \\
& =\sum_{n=b}^{\infty}\left|c_{n-v}\right| \frac{\lambda(n)}{n} \int_{n}^{\infty}(\lambda(w)-\lambda(n))^{k-1} \frac{\mu(w)}{\lambda^{k+1}(w)} d w \\
& =\frac{1}{k} \sum_{n=b}^{\infty} \frac{\left|c_{n-v}\right|}{n} \leqq \frac{1}{k} \frac{d(u)}{b} \\
& =O\left(1 / v P_{v}\right),
\end{aligned}
$$

by Lemma 2 (ii), (iv), and Lemma 3. Hence (3.1) is proved.

This completes the proof of the theorem.

By putting $p_{n}=1 /(n+1), \lambda(w)=w$ (integer) we get the inclusion $|N, 1 /(n+1)| \subset|R, n, k|, k>0$ due to McFadden [4].

My thanks are due to Prof. T. Pati for his suggestion and also to the referee for his valuable comments.

\section{REFERENCES}

1. G. Das, Tauberian theorems for absolute Nörlund summability, Proc. London Math. Soc., (3), XIX, Part II, (1969), 357-384.

2. G. H. Hardy, Divergent Series, Oxford (1949).

3. J. M. Hyslop, On the absolute summability of series by Riesz means, Proceedings of the Edinburg Math. Soc., 5 (1936), 46-54.

4. L. McFadden, Absolute Nörlund summability, Duke Math. J., 9 (1942), 168-207.

5. F. M. Mears, Some multiplication theorems for the Nörlund means, Bull. Amer. Math. Soc., 41 (1935), 875-880.

6. - Absolute regularity and the Nörlund means, Annals of Math., 38 (1937), $594-601$.

7. N. E. Nörlund, Sur une application des function permutable, Lunds Universities Arsskrift (2), 6 (1919), No. 3.

8. N. Obrechkoff, Sur la sommation absolute des series de Dirichlet, Comptes Rendus, 186 (1928), 215-217.

9. — Uber die sbsolute summierung der Disichletschen Reihen, Mathematische Zeischrift, 30 (1929), 375-386.

Received December 23, 1975 and in revised form September 6, 1978.

SAMBALPUR UNIVERSiTY

JYOTI VIHAR, BURLA

SAMBALPUR, ORISSA

768017 (INDIA) 



\section{PACIFIC JOURNAL OF MATHEMATICS}

\section{EDITORS}

Donald BABBITT (Managing Editor)

University of California

Los Angeles, CA 90024

HUGo RossI

University of Utah

Salt Lake City, UT 84112

C. C. MOORE and ANDREW OGG

University of California

Berkeley, CA 94720

\section{J. DuGUNDJI}

Department of Mathematics

University of Southern California

Los Angeles, CA 90007

R. FINN and J. Milgram

Stanford University

Stanford, CA 94305

ASSOCIATE EDITORS
E. F. BECKENBACH
B. H. NeumanN
F. WOLF
K. YoSHIDA

\section{SUPPORTING INSTITUTIONS}

\author{
UNIVERSITY OF BRITISH COLUMBIA \\ CALIFORNIA INSTITUTE OF TECHNOLOGY \\ UNIVERSITY OF CALIFORNIA \\ MONTANA STATE UNIVERSITY \\ UNIVERSITY OF NEVADA, RENO \\ NEW MEXICO STATE UNIVERSITY \\ OREGON STATE UNIVERSITY \\ UNIVERSITY OF OREGON
}

\author{
UNIVERSITY OF SOUTHERN CALIFORNIA \\ STANFORD UNIVERSITY \\ UNIVERSITY OF HAWAII \\ UNIVERSITY OF TOKYO \\ UNIVERSITY OF UTAH \\ WASHINGTON STATE UNIVERSITY \\ UNIVERSITY OF WASHINGTON
}

The Supporting Institutions listed above contribute to the cost of publication of this Journal, but they are not owners or publishers and have no responsibility for its content or policies.

Mathematical papers intended for publication in the Pacific Journal of Mathematics should be in typed form or offset-reproduced, (not dittoed), double spaced with large margins. Please do not use built up fractions in the text of the manuscript. However, you may use them in the displayed equations. Underline Greek letters in red, German in green, and script in blue. The first paragraph or two must be capable of being used separately as a synopsis of the entire paper. Please propose a heading for the odd numbered pages of less than 35 characters. Manuscripts, in triplicate, may be sent to any one of the editors. Please classify according to the scheme of Math. Reviews, Index to Vol. 39. Supply name and address of author to whom proofs should be sent. All other communications should be addressed to the managing editor, or Elaine Barth, University of California, Los Angeles, California, 90024.

50 reprints to each author are provided free for each article, only if page charges have been substantially paid. Additional copies may be obtained at cost in multiples of 50 .

The Pacific Journal of Mathematics is issued monthly as of January 1966. Regular subscription rate: $\$ 84.00$ a year (6 Vols., 12 issues). Special rate: $\$ 42.00$ a year to individual members of supporting institutions.

Subscriptions, orders for numbers issued in the last three calendar years, and changes of address should be sent to Pacific Journal of Mathematics, P.O. Box 969, Carmel Valley, CA 93924, U.S.A. Older back numbers obtainable from Kraus Periodicals Co., Route 100, Millwood, NY 10546.

PUBLISHED BY PACIFIC JOURNAL OF MATHEMATICS, A NON-PROFIT CORPORATION

Printed at Kokusai Bunken Insatsusha (International Academic Printing Co., Ltd.). 8-8, 3-chome, Takadanobaba, Shinjuku-ku, Tokyo 160, Japan.

Copyright (C) 1979 by Pacific Journal of Mathematics Manufactured and first issued in Japan 


\section{Pacific Journal of Mathematics}

\section{Vol. 82 , No. 2 \\ February, 1979}

Krishnaswami Alladi and Paul Erdős, On the asymptotic behavior of large prime

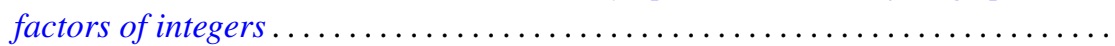

Alfred David Andrew, A remark on generalized Haar systems in $L_{p}$,

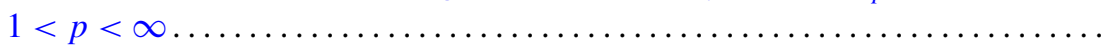

John M. Baker, A note on compact operators which attain their norm . . ........

Jonathan Borwein, Weak local supportability and applications to

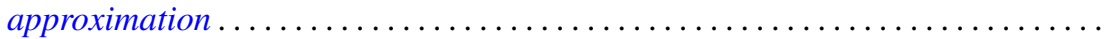

Tae Ho Choe and Young Soo Park, Wallman's type order compactification ........

Susanne Dierolf and Ulrich Schwanengel, Examples of locally compact

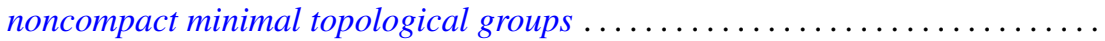

Michael Freedman, A converse to (Milnor-Kervaire theorem) $\times R$ etc. . . . . . . .

George Golightly, Graph-dense linear transformations ..................

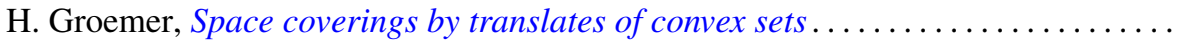

Rolf Wim Henrichs, Weak Frobenius reciprocity and compactness conditions in

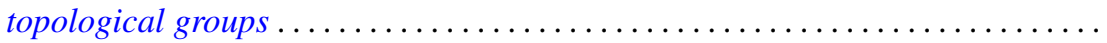

Horst Herrlich and George Edison Strecker, Semi-universal maps and universal

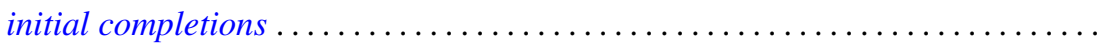

Sigmund Nyrop Hudson, On the topology and geometry of arcwise connected,

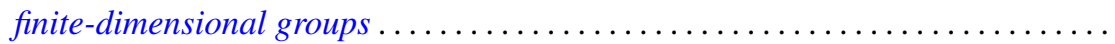

K. John and Václav E. Zizler, On extension of rotund norms. II .............

Russell Allan Johnson, Existence of a strong lifting commuting group of transformations. II.

Bjarni Jónsson and Ivan Rival, Lattice varieties covering the smallest nonmodular variety

Grigori Abramovich Kolesnik, On the order of Dirichlet L-functions .

Robert Allen Liebler and Jay Edward Yellen, In search of nonsolvable groups of

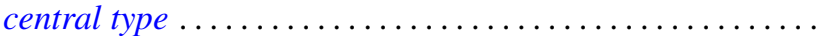

Wilfrido Martínez T. and Adalberto Garcia-Maynez Cervantes, Unicoherent plane Peano sets are $\sigma$-unicoherent ...

M. A. McKiernan, General Pexider equations. I. Existence of injective

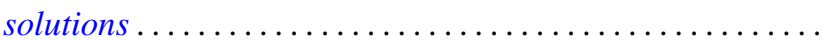

M. A. McKiernan, General Pexider equations. II. An application of the theory of webs.

Jan K. Pachl, Measures as functionals on uniformly continuous functions . .

Lee Albert Rubel, Convolution cut-down in some radical convolution algebras ...

Peter John Slater and William Yslas Vélez, Permutations of the positive integers

with restrictions on the sequence of differences. II . . .

Raymond Earl Smithson, A common fixed point theorem for nested spaces ....

Indulata Sukla, Generalization of a theorem of McFadden .... . . .

Jun-ichi Tanaka, A certain class of total variation measures of analytic measures.

Kalathoor Varadarajan, Modules with supplements .............. 